\title{
The investigation and diagnosis of pulmonary hypertension in adults with congenital heart disease
}

\author{
Heba Nashat ${ }^{1,2}$, Carla Favoccia ${ }^{1}$, Andrew Constantine ${ }^{1,2}$ and Konstantinos Dimopoulos ${ }^{1,2^{*}}$ (D)
}

\begin{abstract}
Pulmonary hypertension is not uncommon in adult patients with congenital heart disease and can significantly affect their exercise capacity, quality of life and prognosis. Timely identification and management of pulmonary hypertension in these patients is important. Patients must be allocated to the correct diagnostic group and treatment decided upon, including offering pulmonary arterial hypertension therapies to those who are most likely to benefit.

In this paper, we provide an overview of the diagnostic modalities that are used to investigate and diagnose pulmonary hypertension in modern adult congenital heart disease practice. Emphasis is placed on echocardiography, which is the modality of choice for raising the suspicion of $\mathrm{PH}$, and cardiac catheterisation, which is fundamental in establishing the diagnosis. Other modalities, such as cardiac magnetic resonance imaging and computed tomography can provide complementary information on anatomy and physiology.

Combining all this information into a clinical diagnosis and management plan requires clinical expertise and a multidisciplinary approach, especially when managing this rare and complex group of patients.
\end{abstract}

Keywords: Pulmonary hypertension, Congenital heart disease

\section{Background}

Pulmonary hypertension $(\mathrm{PH})$ is common in adults with congenital heart disease (CHD). The definition and classification of $\mathrm{PH}$ observes the most recent recommendations of the 6th World Symposium on Pulmonary Hypertension (WSPH) held in 2018. PH is now defined as mean pulmonary arterial pressure (PAP) $>20 \mathrm{mmHg}$ at right heart catheterisation, and is classified into 5 groups that share similar pathological, hemodynamic and therapeutic approaches. Group 1; pulmonary arterial hypertension (PAH), describes a small proportion of $\mathrm{PH}$ patient who in addition to a PAP $>20 \mathrm{mmHg}$, include the additional requisite of a pulmonary wedge pressure of $<15 \mathrm{mmHg}$

\footnotetext{
*Correspondence: k.dimopoulos02@gmail.com

${ }^{1}$ Adult Congenital Heart Disease Centre and National Centre for Pulmonary Hypertension, Royal Brompton Hospital, London, UK

${ }^{2}$ National Heart and Lung Institute, Imperial College, London, UK
}

and pulmonary vascular resistance ( PVR) of > 3 Wood units (WU). Those with PAH includes Eisenmenger syndrome (ES) and other types of $\mathrm{PAH}$ associated with CHD (PAH-CHD). Group 2; secondary to left heart disease (i.e. disease of the systemic ventricle or valves, or left-sided obstructive lesions). Group 3; secondary to lung disease (developmental abnormalities which can be associated with CHD). Group 4; chronic thromboembolic pulmonary hypertension (CTEPH) and other pulmonary artery obstructions. Lastly, group 5; $\mathrm{PH}$ with unclear or multifactorial mechanisms, which includes segmental PH, see article by $\mathrm{R}$ Condliffe entitled "Pulmonary Arterial Hypertension associated with Congenital Heart Disease: Classification and Pathophysiology" in this issue) [1].

Epidemiological data are scarce but, at present, it is estimated that $5-10 \%$ of patients with CHD may develop any form of $\mathrm{PH}[2-4]$. It is associated with an adverse

(c) The Author(s). 2020 Open Access This article is licensed under a Creative Commons Attribution 4.0 International License, which permits use, sharing, adaptation, distribution and reproduction in any medium or format, as long as you give appropriate credit to the original author(s) and the source, provide a link to the Creative Commons licence, and indicate if changes were made. The images or other third party material in this article are included in the article's Creative Commons licence, unless indicated otherwise in a credit line to the material. If material is not included in the article's Creative Commons licence and your intended use is not permitted by statutory regulation or exceeds the permitted use, you will need to obtain permission directly from the copyright holder. To view a copy of this licence, visit http://creativecommons.org/licenses/by/4.0/ The Creative Commons Public Domain Dedication waiver (http://creativecommons.org/publicdomain/zero/1.0/) applies to the data made available in this article, unless otherwise stated in a credit line to the data. 
outcome in CHD, but survival improves when patients are diagnosed early and managed in expert centres. More so, those with PAH have better outcomes when treated with disease targeted pulmonary vasodilators [5].

The diagnosis of $\mathrm{PH}$ requires clinical suspicion based on symptoms, physical examination and knowledge of risk factors related to its development. Clinical suspicion triggers a series of non-invasive investigations, which establish the probability of $\mathrm{PH}$, identify its aetiology and define its impact on the heart, lungs and other organs. Investigations culminate with cardiac catheterisation, which provides the haemodynamic basis for a definitive diagnosis of $\mathrm{PH}$ and $\mathrm{PAH}$. The interpretation of these investigations is best achieved in a multidisciplinary environment, which includes expertise in adult CHD and $\mathrm{PH}$, cardiovascular and respiratory imaging, exercise physiology and invasive haemodynamics.

In this paper, we discuss the investigations, both invasive and non-invasive, performed to diagnose $\mathrm{PH}$ and $\mathrm{PAH}$ in patients with CHD, with particular emphasis on echocardiography and cardiac catheterisation.

\section{History and examination}

The presentation of $\mathrm{PH}$ is varied but often lacks specificity, as symptoms of $\mathrm{PH}$ are shared by other common cardiovascular and respiratory disorders, and may also be related to CHD: dyspnoea, syncope on effort, angina, fatigue and progressive limitation of exercise capacity. $\mathrm{PH}$ should be suspected in patients with symptoms that are out of keeping with the degree of heart disease or other comorbidities. Therefore, awareness of $\mathrm{PH}$ is important in triggering investigations and avoiding a delay in diagnosis, which unfortunately remains common [1].

The physical signs of $\mathrm{PH}$ are often confounded by the presence CHD. Clinical signs of PH may include a parasternal lift, an accentuated pulmonary component of the second heart sound, a right ventricular (RV) third heart sound, a pan-systolic murmur of tricuspid regurgitation or diastolic murmur of pulmonary regurgitation. Raised right atrial (RA) pressure may be detected as hepatic congestion (hepatomegaly), increased jugular venous pressure, peripheral oedema and abdominal ascites. In advanced disease, the peripheries may be cool, with a low volume pulse due to a reduced cardiac output [1].

In patients with ES, cyanosis is typically present at rest or on minimal effort. The cyanosis is typically, but not always, associated with digital clubbing. In patients with a patent ductus arteriosus (PDA), classic cyanosis and clubbing may only be seen in the lower extremities (differential cyanosis and clubbing). Long-standing cyanosis is associated with iron deficiency, and predisposes to thrombosis and bleeding, gout, renal dysfunction, cholelithiasis and cerebral abscesses [6].

\section{Electrocardiography}

A 12-lead electrocardiogram (ECG) can be useful in helping to identify $\mathrm{PH}$ in $\mathrm{CHD}$ patients, even though many of the changes consistent with $\mathrm{PH}$ are also present in $\mathrm{CHD}$ patients without $\mathrm{PH}$. P pulmonale, right QRS axis deviation, RV hypertrophy and right bundle branch block can be signs of $\mathrm{PH}$ but are also common in CHD patients with other right-sided lesions (Fig. 1). Supraventricular (and ventricular) arrhythmias are not uncommon in $\mathrm{PAH}-$ CHD, with a yearly incidence of up to $4 \%$, and are associated with an adverse mid-to-long-term outcome [7]. Therefore, the ECG may be helpful when signs of PH are observed in patients without other causes of RV hypertrophy or RA dilatation. Moreover, ECGs should be routinely performed in PAH-CHD patients, to identify rhythm abnormalities and aid in risk stratification.

\section{Chest radiography}

Chest radiographs can provide a wealth of information when assessing CHD patients, including information on situs, the position and size of the heart, size of the great vessels, previous surgery or intervention and the presence of coexistent lung disease. Patients with advanced PAH typically present with pulmonary arterial dilatation, decreased peripheral lung vascular markings (pruning), RA and RV enlargement (Fig. 2). Calcification at the site of a PDA may be present in adults with ES related to a large duct [8]. The chest radiograph can also help rule out pulmonary congestion, pleural effusion or consolidation in the presence of a lower respiratory tract infection or haemoptysis. Other useful information derived from chest radiography includes thoracic skeletal abnormalities, such as scoliosis, and lung fibrosis, which may prompt further investigations and complement management (e.g. noninvasive ventilation). A normal chest radiograph does not exclude PAH and the severity of the disease does not always correlate to radiographic findings $[9,10]$.

\section{Echocardiography}

While cardiac catheterisation is essential in establishing the diagnosis of $\mathrm{PH}$, echocardiography plays a crucial role in raising the suspicion of $\mathrm{PH}$ and formulating a probability of $\mathrm{PH}$, which together with other signs, drives the clinical decision to proceed to cardiac catheterisation. International guidelines provide firm recommendations on the use of echocardiography to support the diagnosis of $\mathrm{PH}$, which focus around the use of continuous wave Doppler measurement of peak tricuspid regurgitation velocity (TRV). Sources of error derive from insufficient, technically poor tricuspid regurgitation Doppler signals and inaccurate estimation of RA pressure, which should be added to the tricuspid regurgitation gradient to estimate RV systolic pressure [11]. Additional signs of $\mathrm{PH}$ are also proposed, and relate to the ventricles, the 


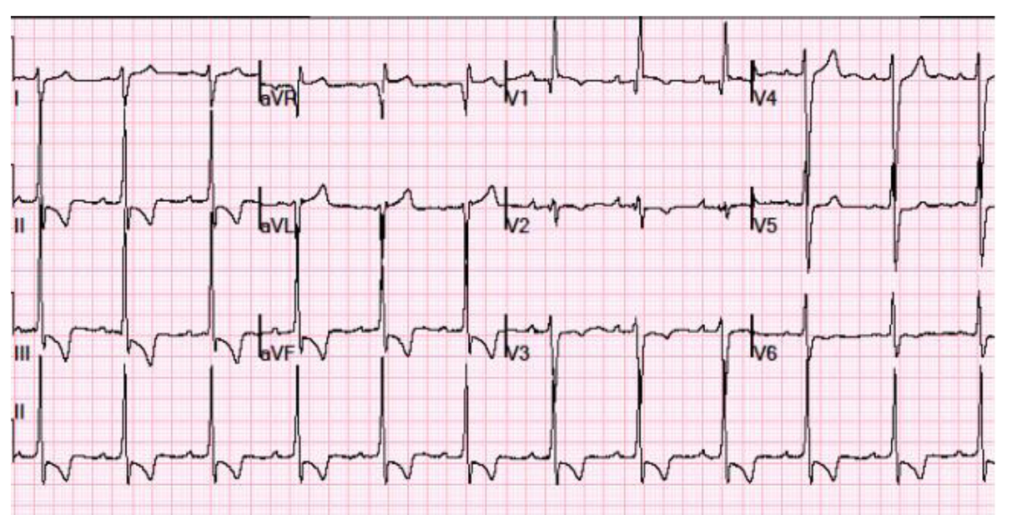

Fig. 1 ECG shows sinus rhythm 69 bpm with a first-degree atrioventricular block with a PR interval of 200 ms and right ventricular hypertrophy

pulmonary artery, inferior vena cava and right atrium (Table 1; Fig. 3) [1].

While some of these parameters often apply to CHD patients, there are several exceptions. A raised TRV, RV hypertrophy and RA dilation are likely to be present in patients with RV outflow tract obstruction / pulmonary stenosis, in the absence of PH. TRV cannot be used to estimate pulmonary artery (PA) pressures in patients with

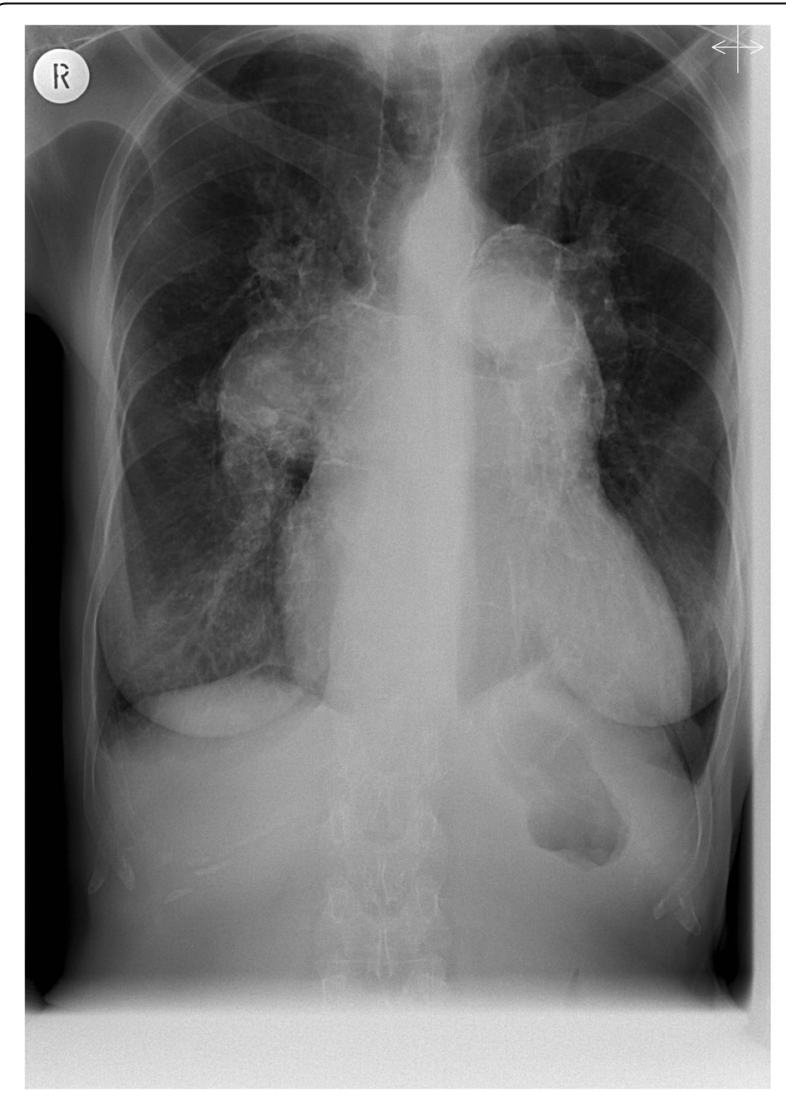

Fig. 2 Chest radiograph illustrating cardiomegaly and dilated pulmonary arteries in a patient with Eisenmenger syndrome univentricular circulation, or in patients with a systemic $\mathrm{RV}$, i.e. those with congenitally corrected transposition of the great arteries (TGA) or atrial switch repair for TGA. In both groups, the pulmonary regurgitation Doppler may prove useful. In the systemic RV group, the peak mitral regurgitation Doppler velocity can be used in place of the TRV. Therefore, curating all of the available echocardiographic signs of PAH in CHD requires significant expertise and should be performed in specialist centres [12].

A formal PH diagnosis can only be established through cardiac catheterisation, which can also assess post-capillary haemodynamics. In a clear-cut case of an adult patient with ES with a post-tricuspid shunt, however, some expert centres may avoid cardiac catheterisation (e.g. a large ventricular septal defect with low-velocity bidirectional shunting and chronic cyanosis in the absence of significant obstruction of flow towards the pulmonary circulation, Fig. 4) [13].

\section{Pulmonary function testing}

The symptoms of $\mathrm{PH}$ overlap with those of parenchymal lung diseases. Therefore, pulmonary function tests (PFTs) should always be carried out as part of the diagnostic workup of patients with possible $\mathrm{PH}$. Abnormal lung function is common in CHD patients, especially in those with skeletal abnormalities, complex CHD and previous thoracotomies [14] These may contribute to symptoms or to the development of PH and should be sought and treated $[15,16]$.

\section{Computed tomography and ventilation/perfusion lung scanning}

Computed tomography (CT) offers excellent spatial resolution and is widely available, with a much shorter acquisition time than cardiac magnetic resonance imaging (CMR). PA dilatation (>29 mm) is frequently seen in those with PAH. A CT pulmonary angiogram can clearly delineate the pulmonary vascular anatomy and detect CHD (e.g. a PDA or aortopulmonary window, peripheral pulmonary stenosis, abnormal systemic or 
Table 1 "Other" echocardiographic signs of $\mathrm{PH}$, beyond tricuspid regurgitation velocity

\begin{tabular}{|c|c|c|}
\hline Ventricles & $\mathrm{RV} / \mathrm{LV}$ basaldiameter ratio $>1.0$ & $\begin{array}{l}\text { Flattening of the IVS (LV eccentricity } \\
\text { index }>1.1 \text { in systole and/or diastole) }\end{array}$ \\
\hline Pulmonary artery & $\begin{array}{l}\text { RV outflow Doppler acceleration time }<105 \mathrm{~ms} \text { and/or } \\
\text { mid-systolic notching }\end{array}$ & $\begin{array}{l}\text { Early diastolic PR velocity }>2.2 \mathrm{~m} / \mathrm{s} \text { AND } \\
\text { PA dimension }>25 \mathrm{~mm}\end{array}$ \\
\hline Inferior vena cava and right atrium & $\begin{array}{l}\text { IVC dimension }>21 \mathrm{~mm} \text { with decreased inspiratory } \\
\text { collapse }(<50 \% \text { with a sniff or }<20 \% \text { with quiet inspiration) }\end{array}$ & RA area (end-systole) $>18 \mathrm{~cm}^{2}$ \\
\hline
\end{tabular}

Reproduced with permission of the $\odot$ ESC \& ERS 2019. European Respiratory Journal Oct 2015, 46 (4) 903-975; 10.1183/13993003.01032-2015 [1] Abbreviations: IVC Inferior vena cava, IVS Inter-ventricular septum, LV Left ventricle, PA Pulmonary artery, PR Pulmonary regurgitation, RA Right atrium, $R V$ Right ventricle [1]

pulmonary venous drainage and aortopulmonary or veno-venous collateral vessels), pulmonary emboli or in-situ thrombosis. A CT can rule out other causes of $\mathrm{PH}$, such as interstitial lung disease, severe emphysema or proximal chronic thromboembolic pulmonary hypertension $(\mathrm{CTEPH})$. Indeed, spectral-detector CT may offer an alternative to single-photon emission computed tomography ventilation-perfusion (SPECT $\mathrm{V} / \mathrm{Q})$, which is the current standard investigation for CTEPH. Finally, CT coronary angiography is routinely used nowadays to define the origin and distribution of the coronary arteries, the anatomy of the great vessels and other cardiac structures, and to exclude ischaemic heart disease [17].

\section{Cardiac magnetic resonance imaging}

CMR is routinely used in the assessment and followup of adults with CHD. Moreover, CMR is increasingly used for assessing patients with $\mathrm{PH}$. It is invaluable in defining intra- and extra-cardiac anatomy and provides important information of ventricular and valve function. CMR allows non-invasive assessment of stroke volume (SV), pulmonary and systemic cardiac output $(\mathrm{CO})$. It is used in some centres at the time of cardiac catheterisation in "hybrid" labs ( catheterisation labs which combine advanced diagnostic imaging with surgical functions of an operating room) to calculate pulmonary vascular resistance (PVR) and shunt fraction (Qp/Qs) [18]. MRI is particularly important in patients with complex CHD and/or multiple sources of pulmonary blood flow.

Prognosis in $\mathrm{PH}$ is greatly driven by $\mathrm{RV}$ function and its response to $\mathrm{PAH}$ therapy, where appropriate. CMR is currently the gold standard for assessing RV function and is superior to echocardiography, which may not adequately visualise the RV free wall and infundibulum $[19,20]$.

\section{Right heart catheterisation}

Cardiac catheterisation remains the only way to confirm and accurately classify $\mathrm{PH}$ in most cases. At cardiac catheterisation, $\mathrm{PH}$ is defined as a mean pulmonary arterial pressure (mPAP) of $\geq 25 \mathrm{mmHg}$, [1] although recently a new definition has been proposed based on a lower mPAP cut-off of $>20 \mathrm{mmHg}$, incorporating a PVR of $\geq 3 \mathrm{WU}$ in those with $\mathrm{PAH}$ [21]. Based on the current ESC guidelines, patients are further delineated into pre- $(\leq 15 \mathrm{mmHg})$ and post-capillary (>15 mmHg) haemodynamics $\mathrm{PH}$ based on the pulmonary artery wedge pressure (PAWP) or direct left atrial pressure. Pre-capillary $\mathrm{PH}$ includes patients with $\mathrm{PAH}$, but also patients in group 3 (lung

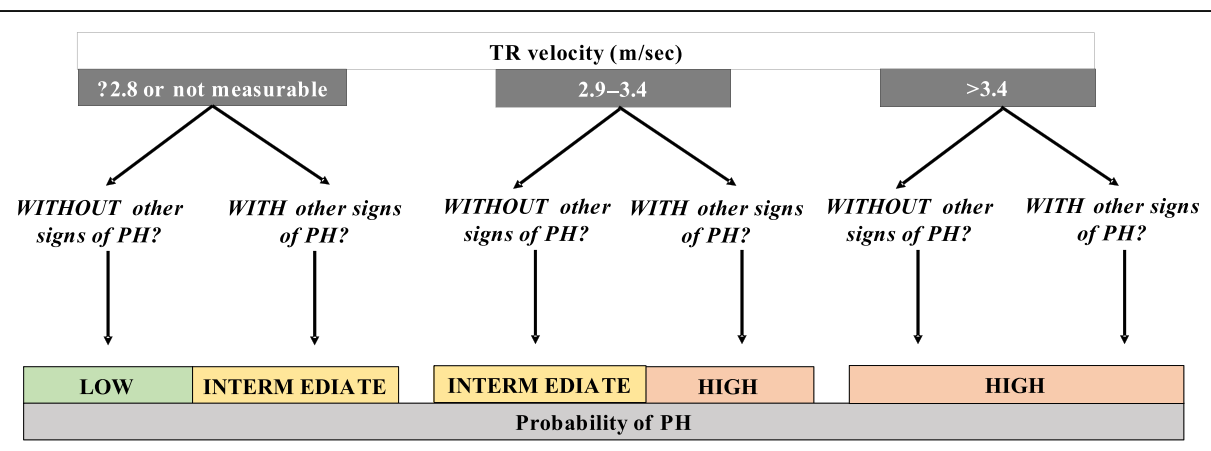

Fig. 3 The probability of PH based on echocardiography and the presence of signs of PH. Abbreviations: TR; tricuspid regurgitation, PH; pulmonary hypertension. Reproduced with permission of the @ ESC \& ERS 2019. European Respiratory Journal Oct 2015, 46 (4) 903-975; https://doi.org/10.1183/13993003.01032-2015 [1] 


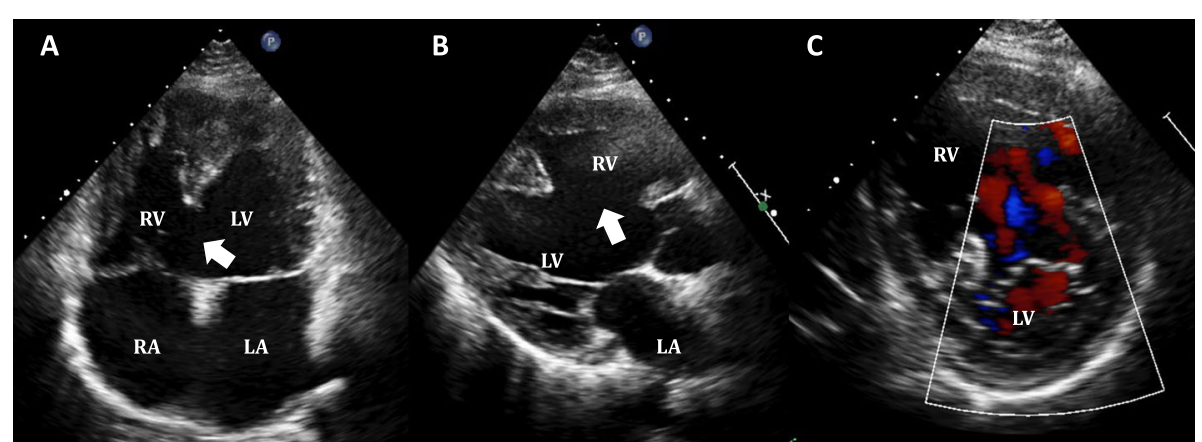

Fig. 4 a Transthoracic echocardiography (4 chamber view) illustrating a large ventricular septal defect (VSD, arrow) and right ventricular hypertrophy. b Parasternal long axis view illustrating the large VSD (arrow). c A short axis view showing low-velocity bidirectional shunting, characteristic of Eisenmenger syndrome

disease), group 4 (e.g. CTEPH) and group 5 (multifactorial $\mathrm{PH})$. Patients with a post-capillary $\mathrm{PH}$ may have isolated post-capillary, or combined pre- and post-capillary $\mathrm{PH}$, with a diastolic pressure gradient (DPG; diastolic PA pressure - mean PAWP) $\geq 7 \mathrm{mmHg}$ and/or PVR $>3$ Wood units (Table 2).

Usually the type of $\mathrm{PH}$ is confirmed based on the hemodynamic data, this has important implications for the patient further management and prognosis. Raised pulmonary arterial pressures $(>25 \mathrm{mmHg}$ ) can have many causes and mechanisms as outlined before, and medical management is tailored accordingly, such as diuresis in left heart failure, treatment of parenchymal lung disease or relief of left heart obstruction. However, if in addition the pulmonary vascular resistance is high (>3WU) in the case of $\mathrm{PAH}$, the resistance of blood from the pulmonary artery to the left atrium is high, is due to increased vascular tone and reduced vascular compliance, induced by numerous pathological mechanisms. This increased vasoconstriction, can be targeted by pulmonary vasodilators such as phosphodiesterase type 5 inhibitors, endothelin receptor antagonists or prostanoid therapy. In those with $\mathrm{PH}$ without a raised PVR, pulmonary vasodilators are not recommended and make things worse.

The interpretation of invasive haemodynamic data should always be made in the context of the clinical history, presentation, and results from other noninvasive investigations. Haemodynamic assessment of patients with CHD should be performed in expert centres, ensuring adequate quality control with accurate acquisition and interpretation of data, especially in the estimation of PVR and shunt fraction [22].

\section{Keys to successful haemodynamic evaluation during catheterisation}

Successful catheterisation requires careful preparation, appropriate hardware selection and meticulous calibration. Swan-Ganz balloon tipped catheters are typically used to measure pressure and to obtain blood samples for oxygen saturations. In a patient with usual anatomy, serial measurements and sampling are taken at the following levels: inferior vena cava, high and low superior vena cava, right atrium, RV, main pulmonary artery and branches (when required). Systemic saturations should ideally also be measured at pulmonary venous and left atrial levels (when an atrial septal defect or patent foramen ovale is present), left ventricle and aorta (when arterial access is obtained). When an atrial communication is not present, and in the absence of right-left shunting (e.g. confirmed by contrast echocardiography), non-invasive arterial saturations may be used for calculations. Serial sampling ("the oximetry run") is important in patients with CHD to detect and quantify a shunt. For left-right shunts, a 'step-up' in saturations is observed

Table 2 Hemodynamic classification of pre- and post-capillary pulmonary hypertension

\begin{tabular}{llll}
\hline Pulmonary Hypertension & Pre-capillary PH & Isolated post-capillary PH & Combined post-capillary and pre-capillary PH \\
\hline $\mathrm{mPAP}^{2} \mathrm{mmHg}^{\text {a }}$ & $\mathrm{mPAP}>20 \mathrm{mmHg}$ AND & $\mathrm{mPAP}>20 \mathrm{mmHg}$ AND & $\mathrm{mPAP}>20 \mathrm{mmHg}$ AND PAWP $>15 \mathrm{mmHg}$ with \\
& PAWP $\leq 15 \mathrm{mmHg}{ }^{\text {a }}$ & PAWP $>15 \mathrm{mmHg}{ }^{\text {a }}$ & DPG $\geq 7 \mathrm{mmHg}$ AND/OR PVR $\geq 3$ WU ${ }^{\mathrm{a}}$ \\
\hline
\end{tabular}

Reproduced with permission of the $\odot$ ESC \& ERS 2019. European Respiratory Journal Oct 2015, 46 (4) 903-975; 10.1183/13993003.01032-2015 [1] Abbreviations: mPAP Mean pulmonary artery pressure, PAWP Pulmonary artery wedge pressure, PH Pulmonary hypertension, PVR Pulmonary vascular resistance [1] ${ }^{\text {a }}$ A new haemodynamic definition has been proposed recently in the Proceedings of the $6^{\text {th }}$ World Symposium on PH [21] 
within the "right" heart (Fig. 5). Mixed venous oxygen saturation is estimated using the formula: mixed venous oxygen saturation $=(3 \mathrm{x}$ high superior vena cava $(\mathrm{SVC})$ saturation + inferior vena cava (IVC) saturation)/4, although many experts prefer using high SVC as mixed venous saturation to avoid contamination from regurgitant saturated blood into the inferior vena cava, e.g. in patients with tricuspid regurgitation. When taking blood samples for oxygen saturations, adequate sampling and mixing with heparin (as recommended by the syringe manufacturer), avoiding contamination by air bubbles in the sampling syringe and haemolysis by excessively vigorous mixing, is advised to avoid pre-analytical error. Other errors that may occur during haemodynamic assessment are related to the position and calibration of the pressure transducer. This should be placed at the mid-thoracic level, ideally using a spirit level or similar device. The pressure transducer should be "zeroed" electronically, and this should be rechecked immediately before acquiring readings. Careful pressure transducer calibration is particularly important in cases of borderline $\mathrm{PH}$ and when measuring left atrial (or PAWP), as small errors can lead to incorrect classification and erroneous treatment, especially when there is significant respiratory "swing", suboptimal wedging (over or under-wedging), calibration or damping [23].

\section{Key haemodynamic parameters in patients with $\mathrm{PAH}$ related to $\mathrm{CHD}$}

During the invasive work up of patients with $\mathrm{PH}$, a series of parameters should be measured (Table 2):
1 Pulmonary arterial pressure (PAP) is key to diagnosing $\mathrm{PH}$. Patients with a mPAP $>20 \mathrm{mmHg}$ are diagnosed as having $\mathrm{PH}$, which could be precapillary or post-capillary. It is important to remember that a rise in PA pressure could also be related to increased pulmonary blood flow (Qp) in the presence of a significant left-right shunt [13].

2 PAWP is key for distinguishing between pre- and post-capillary PH. A PAWP > $15 \mathrm{mmHg}$ is suggestive of post-capillary $\mathrm{PH}$, and reflects raised left atrial or pulmonary venous pressures, which often result from systemic ventricular dysfunction, valve disease or obstructive lesions.

3 RA pressure (and RV end-diastolic pressure) is important in understanding RV filling pressures. $\mathrm{PH}$ results in progressive RA dilatation and a rise in RA pressure. Adequate but not excessive diuresis is important for avoiding peripheral congestion, while allowing adequate RV preload.

4. Cardiac output: In the presence of a shunt, it is important to distinguish between pulmonary (Qp) and systemic blood flow (Qs), the latter of which is equivalent to the cardiac output. The methods used to measure Qp and Qs include the Fick principle and CMR. Thermodilution should be avoided in the presence of intracardiac shunts. The Fick principle is most accurate when oxygen consumption $\left(\mathrm{VO}_{2}\right)$ is measured at the time of the catheter (direct Fick method) rather than

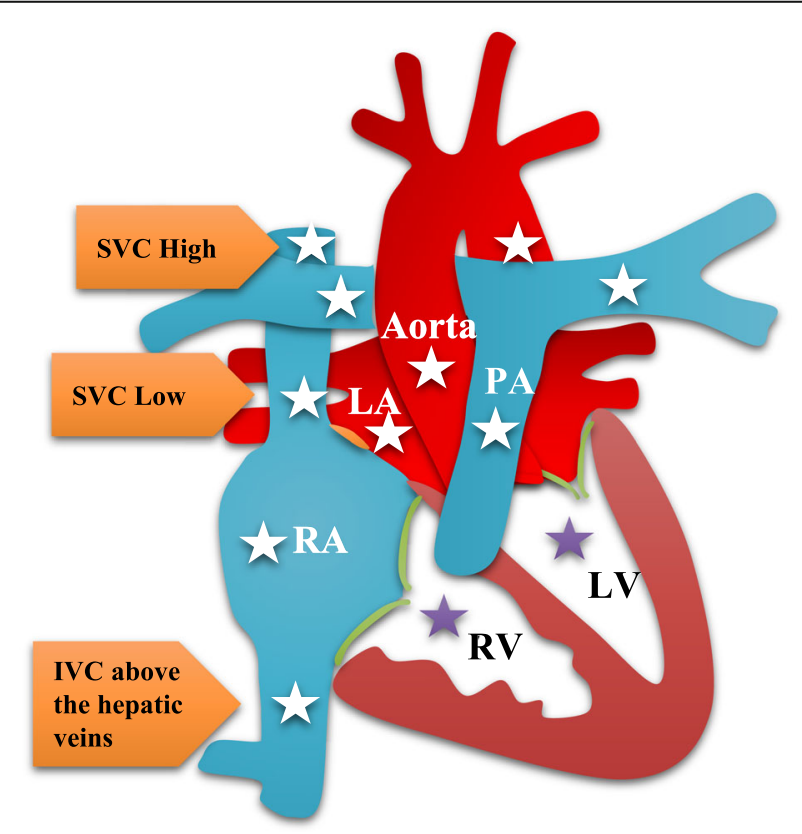

$$
\begin{aligned}
& \text { IVC } \\
& \text { SVC, innominate } \\
& \text { SVC, at RA }
\end{aligned}
$$

RA

LA

$\mathrm{RV}$, mid

RV, apex

$\mathrm{RV}$, outflow tract

PA main

$\mathrm{PA}$, right or left

Left ventricle

Aorta, ascending

Aorta, distal to ductus

Fig. 5 Oximetry run for shunt detection and measurements. Abbreviations: IVC; inferior vena cava, SVC; superior vena cava, RA; right atrium, LA; left atrium RV; right ventricle, PA; pulmonary artery 
taken from nomograms that add to the error (indirect Fick method).

Flowthroughacircuit $=\frac{\mathrm{O}_{2} \text { consumption }\left(\mathrm{VO}_{2}\right)}{\text { ArterialO } \mathrm{O}_{2} \text { content }- \text { venous } \mathrm{O}_{2} \text { content }}$

5. Transpulmonary pressure gradient (TPG) is the difference between mean PAP and mean PAWP (or mean left atrial pressure)

6 Diastolic pressure gradient (DPG) is the difference between diastolic PAP and mean PAWP (or mean left atrial pressure)

7 PVR is the quotient of the TPG and Qp (not Qs)

8 PVR indexed (PVRi) is the product of PVR and body surface area (BSA)

9 Systemic vascular resistance (SVR) is the quotient of the difference in mean aortic and mean RA pressure and Qs

\section{Assessment of operability and vasoreactivity testing}

Current guidelines recommend that patients with a PVRi below 4 WU. ${ }^{2}$ can undergo repair of their defect, whereas repair should be avoided in those with a PVRi > 8 WU.m ${ }^{2}$. In the latter group, pulmonary vascular disease is likely to be established and may progress after repair of the defect. Patients with a PVRi between 4 and 8 WU. ${ }^{2}$, fall into the "grey zone", whereby the decision to repair the defect (or not) is case-specific, with no clear consensus on management (Fig. 6). Previous studies and guidelines have used the ratio PVR/SVR when assessing operability, although the accuracy of recommended cut-offs (0.3 or 0.6) remains controversial [24].

Primarily, pulmonary vasoreactivity testing in $\mathrm{PH}$ is used to identify patients who may be suitable for treatment with calcium channel blockers. It also provides useful information regarding prognosis and possibly reparability. The most commonly used vasodilator for reversibility testing is inhaled nitric oxide $(\mathrm{NO})$ at 10 $40 \mathrm{ppm}$ for 5 minutes; alternatives include intravenous epoprostenol, adenosine or inhaled iloprost, but not oxygen. A reduction in the mPAP of $\geq 10 \mathrm{mmHg}$ to reach an absolute value of $\mathrm{mPAP} \leq 40 \mathrm{mmHg}$, with an increased or unchanged cardiac output, is deemed a positive response [1].

The absence of vasoreactivity may be a marker of poor prognosis. Its role in the assessment of patients with regards to suitability for shunt repair i.e. "treat-and-repair" remains unclear. In the instance of a positive reactivity test, calcium channel blockers are only recommended for patients with idiopathic, heritable or drug-induced PAH [16]. There is no evidence to support their use in patients with PAH-CHD and they are absolutely contraindicated in ES.

\section{Novel imaging modalities}

Diagnostic modalities used in routine practice have been discussed so far. However, with advances in medical technology, more cutting-edge imaging modalities are ever advancing. For the evaluation of pulmonary

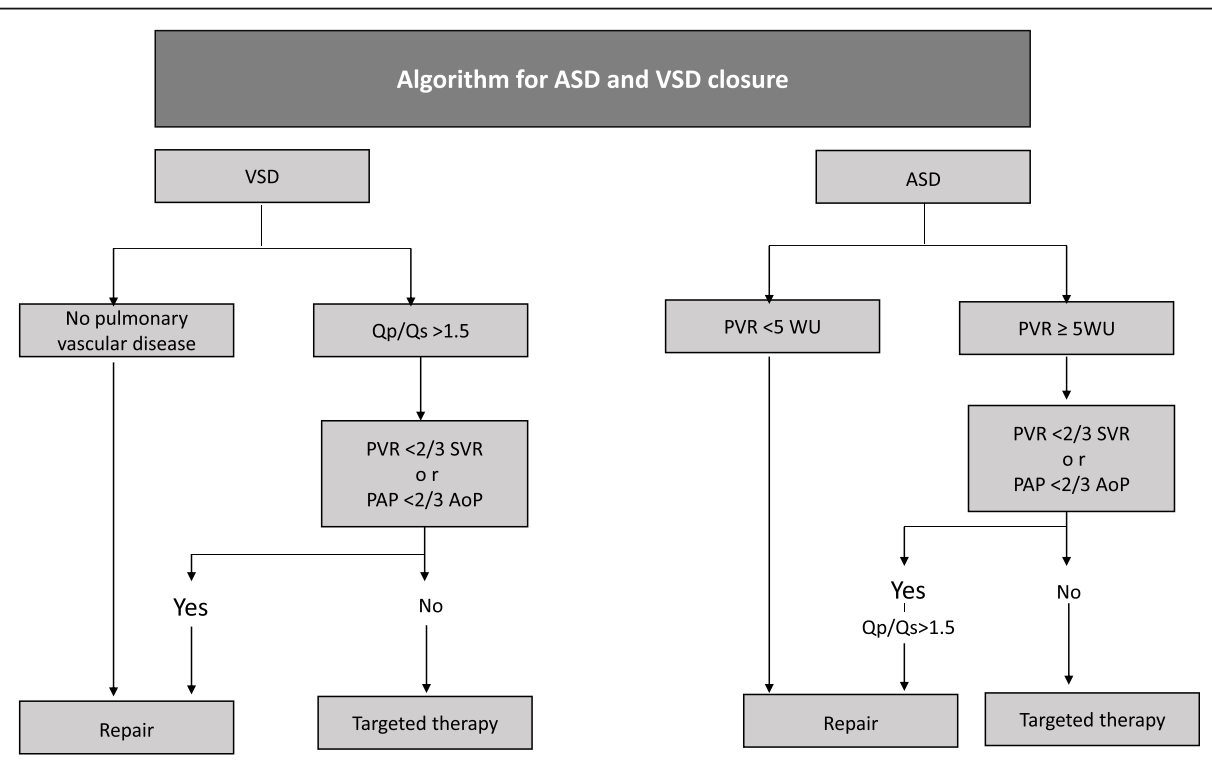

Fig. 6 Treatment algorithm for closure of ASD and VSD, according to ESC GUCH guidelines. These recommendations differ to the recommendations of the ESC/ERS PH guidelines [1] Abbreviations: AoP; aortic pressure, ASD; atrial septal defect, VSD; ventricular septal defect, Qp; pulmonary flow, Qs; systemic flow, PVR; pulmonary vascular resistance, PAP; pulmonary artery pressure, SVR; systemic vascular resistance, WU; Wood units 
embolism or CTEPH, single-photo emission computed tomography/ computed tomography (SPECT/CT) and dual-energy computed tomography (DECT) are emerging. SPECT/CT combines nuclear imaging and CT yielding both anatomical information of PA structures and functional assessment of lung perfusion [25]. Whereas DECT provides lung perfusion analsysis using iodine maps correlated with scintigraphy. DECT has been shown to differentiate between acute and chronic PE. Futhermore, perfusion patterns seen in DECT may be used to identify some forms of PAH such as idiopathic or associated with congenital heart disease [26].

Caridac MRI in pulmonary hypertension provides useful information of both RV and LV anatomy and function. Furthermore, myocardial T1 mapping have been used to identify diffuse myocardial abnormalities and mapping values have been associated wtih indices of RV dysfunction. As this imaging modality develops, it may be a useful tool in determining therapeutic response in $\mathrm{PH}$. Other developing imaging techniques being developed include 4D-flow imaging of the PA, which may provide better understanding into various flow changes that occur in $\mathrm{PH}$ which may enhance prognostic capability [27]. Right ventricular strain mapping has been applied in both transthoracic echocardiography and CMR. Right ventricular function is an important factor in patients with $\mathrm{PH}$. Emerging data indicates that strain analysis may be useful in identifyig early changes in RV function before global dysfunction.

\section{Conclusions}

Routine screening of all CHD patients for $\mathrm{PH}$ is recommended. The clinical suspicion of $\mathrm{PH}$ should be raised based on clinical presentation, underlying anatomy and past medical history. Echocardiography is the primary screening tool for $\mathrm{PH}$ and should be undertaken in specialist CHD centres, keeping in mind that standard echocardiographic signs of $\mathrm{PH}$ have to be adapted in a lesion-specific manner.

The diagnosis of $\mathrm{PH}$ is established through cardiac catheterisation. In CHD, there are many pitfalls, which must be avoided in order to gather accurate, diagnostic data in a safe manner. Once a diagnosis of PAH has been made, PAH therapies should be offered to patients who are eligible, with the aim of improving functional status, quality of life and prognosis.

\footnotetext{
Abbreviations

BSA: Body surface area; CHD: Congenital heart disease; CMR: Cardiac magnetic resonance imaging; CO: Cardiac output; CT: Computed tomography; CTEPH: Chronic thromboembolic pulmonary hypertension; DPG: Diastolic pressure gradient; ECG: 12-lead electrocardiogram; ES: Eisenmenger syndrome; IVC: Inferior vena cava; (m)PAP: (mean) pulmonary arterial pressure; NO: Nitric oxide; PA: Pulmonary artery; $\mathrm{PAH}$ : Pulmonary arterial hypertension; PAH-CHD: Pulmonary arterial hypertension associated with congenital heart disease; PAWP: Pulmonary
}

arterial wedge pressure; PDA: Patent ductus arteriosus; PFTs: Pulmonary function tests; PH: Pulmonary hypertension; PVR(i): Pulmonary vascular resistance (indexed); Qp: Pulmonary blood flow; Qp/Qs: Shunt fraction; Qs: Systemic blood flow; RA: Right atrium; RV: Right ventricle; SPECT V/ Q: Single-photon emission computed tomography ventilation-perfusion; SV: Stroke volume; SVC: Superior vena cava; SVR: Systemic vascular resistance; TGA: Transposition of the great arteries; TPG: Transpulmonary gradient; TRV: Tricuspid regurgitation velocity; $\mathrm{VO}_{2}$ : Oxygen consumption

\section{Acknowledgements}

Not applicable.

\section{About this supplement}

This article has been published as part of Journal of Congenital Cardiology Volume 4 Supplement 1 2020: Unmet needs in Pulmonary Hypertension associated with Adult Congenital Heart Disease (ACHD-PH). The full contents of the supplement are available at https://jcongenitalcardiology. biomedcentral.com/articles/supplements/volume-4-supplement-1.

\section{Authors' contributions}

Authors HN, AC and KD contributed to the conception and planning of the case report. $\mathrm{HN}$ and $\mathrm{CF}$ drafted the manuscript. $\mathrm{HN}, \mathrm{AC}$ and $\mathrm{KD}$ revised the report and finalised. $H N, C F, A C$, and $K D$ approved the final manuscript for publication.

\section{Funding}

Medical writing support was provided by nspm Itd, Meggen, Switzerland. The manuscript was funded by a Medical and Educational Goods and Services (MEGS) grant and Actelion Pharmaceuticals UK Limited (who had no influence on manuscript writing).

\section{Availability of data and materials \\ Not applicable.}

\section{Ethics approval and consent to participate}

We can confirm that consent was gained from the patient as per CARE guidelines. Patient identifying features have been removed from all clinical images to preserve patient anonymity.

\section{Competing interests}

Dr Constantine has received a personal educational grant from Actelion Pharmaceuticals UK. Dr Dimopoulos has received nonfinancial support from Actelion Pharmaceuticals; and has been a consultant to and received grants and personal fees from Actelion Pharmaceuticals, Pfizer, GlaxoSmithKline, and Bayer/MSD. The authors have no other relevant affiliations or financial involvement with any organization or entity with a financial interest in or financial conflict with the subject matter or materials dis- cussed in the manuscript apart from those disclosed.

Received: 12 November 2020 Accepted: 12 November 2020 Published: 16 December 2020

\section{References}

1. Galiè N, Humbert M, Vachiery J-L, Gibbs S, Lang I, Torbicki A, et al. 2015 ESC/ERS Guidelines for the diagnosis and treatment of pulmonary hypertension: the Joint Task Force for the Diagnosis and Treatment of Pulmonary Hypertension of the European Society of Cardiology (ESC) and the European Respiratory Society (ERS) endorsed by: Association for European Paediatric and Congenital Cardiology (AEPC), International Society for Heart and Lung Transplantation (ISHLT). Eur Respir J. 2015: 46(4):903-75. https://doi.org/10.1183/13993003.01032-2015.

2. Duffels MGJ, Engelfriet PM, Berger RMF, van Loon RLE, Hoendermis E, Vriend JWJ, et al. Pulmonary arterial hypertension in congenital heart disease: an epidemiologic perspective from a Dutch registry. Int J Cardiol. 2007;120(2): 198-204. https://doi.org/10.1016/j.ijcard.2006.09.017.

3. van Riel ACMJ, Schuuring MJ, van Hessen ID, Zwinderman AH, Cozijnsen L, Reichert CLA, et al. Contemporary prevalence of pulmonary arterial hypertension in adult congenital heart disease following the updated clinical classification. Int J Cardiol. 2014;174(2):299-305. https://doi.org/10. 1016/j.jijcard.2014.04.072.

4. Dimopoulos K, Diller G-P, Opotowsky AR, D’Alto M, Gu H, Giannakoulas G, et al. Definition and management of segmental pulmonary hypertension. J 
Am Heart Assoc. 2018;7(14):e008587. https://doi.org/10.1161/JAHA.118 008587.

5. Dimopoulos K, Inuzuka R, Goletto S, Giannakoulas G, Swan L, Wort SJ, et al. Improved survival among patients with Eisenmenger syndrome receiving advanced therapy for pulmonary arterial hypertension. Circulation. 2010; 121(1):20-5. https://doi.org/10.1161/circulationaha.109.883876.

6. Nashat H, Kempny A, McCabe C, Price LC, Harries C, Alonso-Gonzalez R, et al. Eisenmenger syndrome: current perspectives. Res Rep Clin Cardiol. 2017:8:1-12. https://doi.org/10.2147/RRCC.S117838.

7. Drakopoulou M, Nashat H, Kempny A, Alonso-Gonzalez R, Swan L, Wort SJ, et al. Arrhythmias in adult patients with congenital heart disease and pulmonary arterial hypertension. Heart Br Card Soc. 2018;104(23):1963-9. doi:https://doi.org/10.1136/heartjnl-2017-312881.

8. Ruskin H, Samuel E. Calcification in the patent doctus arteriosus. Br J Radiol. 1950;23(276):710-7. https://doi.org/10.1259/0007-1285-23-276-710.

9. Sheehan R, Perloff JK, Fishbein MC, Gjertson D, Aberle DR. Pulmonary neovascularity: a distinctive radiographic finding in Eisenmenger syndrome. Circulation. 2005;112(18):2778-85. https://doi.org/10.1161/circulationaha.104. 509869

10. McCann C, Gopalan D, Sheares K, Screaton N. Imaging in pulmonary hypertension, part 1: clinical perspectives, classification, imaging techniques and imaging algorithm. Postgrad Med J. 2012;88(1039):271-9. https://doi. org/10.1136/postgradmedj-2011-130292.

11. Li W, West C, McGhie J, van den Bosch AE, Babu-Narayan SV, Meijboom F, et al. Consensus recommendations for echocardiography in adults with congenital heart defects from the International Society of Adult Congenital Heart Disease (ISACHD). Int J Cardiol. 2018;01:272:77-83. doi:https://doi.org/ 10.1016/j.jijcard.2018.07.058

12. Dimopoulos K, Condliffe R, Tulloh RMR, Clift P, Alonso-Gonzalez R, Bedair R, et al. Echocardiographic screening for pulmonary hypertension in congenital heart disease. J Am Coll Cardiol. 2018;72(22):2778-88. https://doi. org/10.1016/j.jacc.2018.08.2201.

13. Dimopoulos K, Wort SJ, Gatzoulis MA. Pulmonary hypertension related to congenital heart disease: a call for action. Eur Heart J. 2014;35(11):691-700. https://doi.org/10.1093/eurheartj/eht437.

14. Alonso-Gonzalez R, Borgia F, Diller G-P, Inuzuka R, Kempny A, MartinezNaharro A, et al. Abnormal lung function in adults with congenital heart disease: prevalence, relation to cardiac anatomy, and association with survival. Circulation. 2013;26(8):882-90. https://doi.org/10.1161/ circulationaha.112.126755.

15. Broberg CS, Van Woerkom RC, Swallow E, Dimopoulos K, Diller G-P, Allada $G$, et al. Lung function and gas exchange in Eisenmenger syndrome and their impact on exercise capacity and survival. Int J Cardiol. 2014;171(1):737. https://doi.org/10.1016/j.jicard.2013.11.047.

16. Dimopoulos K, Okonko DO, Diller G-P, Broberg CS, Salukhe TV, BabuNarayan SV, et al. Abnormal ventilatory response to exercise in adults with congenital heart disease relates to cyanosis and predicts survival. Circulation. 2006;113(24):2796-802. https://doi.org/10.1161/circulationaha. 105.594218.

17. D'Alto M, Dimopoulos K, Budts W, Diller G-P, Di Salvo G, Dellegrottaglie S, et al. Multimodality imaging in congenital heart disease-related pulmonary arterial hypertension. Heart Br Card Soc. 2016;102(12):910-8. https://doi.org/ 10.1136/heartjnl-2015-308903

18. Jensen AS, Broberg CS, Rydman R, Diller G-P, Li W, Dimopoulos K, et al. Impaired right, left, or biventricular function and resting oxygen saturation are associated with mortality in Eisenmenger syndrome: a clinical and cardiovascular magnetic resonance study. Circ Cardiovasc Imaging. 2015; 8(12):e003596. https://doi.org/10.1161/circimaging.115.003596.

19. van de Veerdonk MC, Marcus JT, Bogaard H-J, Vonk Noordegraaf A. State of the art: advanced imaging of the right ventricle and pulmonary circulation in humans (2013 Grover Conference series). Pulm Circ. 2014;4(2):158-68. https://doi.org/10.1086/675978.

20. van de Veerdonk MC, Marcus JT, Westerhof N, de Man FS, Boonstra A, Heymans MW, et al. Signs of right ventricular deterioration in clinically stable patients with pulmonary arterial hypertension. Chest. 2015;147(4): 1063-71. https://doi.org/10.1378/chest.14-0701.

21. Simonneau G, Montani D, Celermajer DS, Denton CP, Gatzoulis MA, Krowka $M$, et al. Haemodynamic definitions and updated clinical classification of pulmonary hypertension. Eur Respir J. 2019;53(1):1801913. https://doi.org/10. 1183/13993003.01913-2018
22. Tulloh R, Dimopoulos K, Condliffe R, Clift P, CHAMPION Steering Committee. Management of adults with congenital heart disease and pulmonary arterial hypertension in the UK: survey of current practice, unmet needs and expert commentary. Heart Lung Circ. 2018;27(8):1018-27. https://doi.org/10.1016/j. hlc.2017.10.018

23. Rosenkranz S, Preston IR. Right heart catheterisation: best practice and pitfalls in pulmonary hypertension. Eur Respir Rev Off J Eur Respir Soc. 2015; 24(138):642-52. https://doi.org/10.1183/16000617.0062-2015.

24. Dimopoulos K, Peset A, Gatzoulis MA. Evaluating operability in adults with congenital heart disease and the role of pretreatment with targeted pulmonary arterial hypertension therapy. Int J Cardiol. 2008;129(2):163-71. https://doi.org/10.1016/j.ijcard.2008.02.004.

25. Soler X, Kerr KM, Marsh JJ, Renner JW, Hoh CK, Test VJ, Morris Ta. Pilot study comparing SPECT perfusion scintigraphy with CT pulmonary angiography in chronic thromboembolic pulmonary hypertension. Respirology. 2012:17(1): 180-4. https://doi.org/10.1111/j.1440-1843.2011.02061.x.Respirology. 2012. PMID: 21899658

26. Ameli-Renani S, Rahman F, Nair A, Ramsay L, Bacon JL, Weller A, et al. Dual-energy $C T$ for imaging of pulmonary hypertension: challenges and opportunities. Radiographics. 2014;34:1769-90.

27. Reiter U, Reiter G, Kovacs G, Stalder AF, Gulsun MA, Greiser A, Olschewski H, Fuchsjäger M. Evaluation of elevated mean pulmonary arterial pressure based on magnetic resonance $4 \mathrm{D}$ velocity mapping: comparison of visualization techniques. PLoS One. 2013 ;8(12):e82212.https://doi.org/10. 1371/journal.pone.0082212. PMID: 24349224; PMCID: PMC3861394.

\section{Publisher's Note}

Springer Nature remains neutral with regard to jurisdictional claims in published maps and institutional affiliations.

\section{Ready to submit your research? Choose BMC and benefit from:}

- fast, convenient online submission

- thorough peer review by experienced researchers in your field

- rapid publication on acceptance

- support for research data, including large and complex data types

- gold Open Access which fosters wider collaboration and increased citations

- maximum visibility for your research: over $100 \mathrm{M}$ website views per year

At BMC, research is always in progress.

Learn more biomedcentral.com/submissions 